\title{
RAT CORONAVIRUS INFECTION OF PRIMARY RAT ALVEOLAR EPITHELIAL CELLS
}

\author{
Tanya A. Miura, Jieru Wang, Robert J. Mason, and Kathryn V. Holmes*
}

\section{INTRODUCTION}

There are five human coronaviruses $(\mathrm{HCoV})$ that cause respiratory disease. HCoV$229 \mathrm{E}$ and HCoV-OC43 cause upper respiratory tract infections and rarely cause lower respiratory tract disease in immunocompromised patients. In 2002-2003, a novel coronavirus, SARS-CoV, caused a pandemic of severe acute respiratory distress syndrome. Since the SARS epidemic, two additional HCoVs have been identified, HCoV-NL-63 and HCoV-HKU1. HCoV-NL-63 has been isolated from pediatric cases of respiratory disease $\mathrm{e}^{1,2}$ and $\mathrm{HCoV}-\mathrm{HKU} 1$ has been isolated from two adult patients with pneumonia. ${ }^{3}$ Coronaviruses also cause respiratory diseases in other species, including porcine respiratory coronavirus $(\mathrm{PRCoV}){ }^{4}$ respiratory bovine coronavirus (BCoVResp) ${ }^{5}$ and canine respiratory coronavirus $(\mathrm{CRCoV}) .{ }^{6}$ Two strains of rat coronavirus $(\mathrm{RCoV})$ cause respiratory disease in rats. Sialodacryoadenitis virus (RCoV-SDAV) and Parker's rat coronavirus (RCoV-P) have both been isolated from infected rat lungs. We are studying the pathogenesis of $\mathrm{RCoVs}$ as a model for coronavirus respiratory disease in the natural host.

RCoV-SDAV was initially isolated from the salivary glands of rats with sialodacryoadenitis. ${ }^{7}$ In addition to pathogenesis in the salivary and lacrimal glands, RCoV-SDAV can cause chronic eye disease, reproductive disorders, and mild acute disease in the respiratory tract. ${ }^{7-10} \mathrm{RCoV}-\mathrm{SDAV}-$ infected adult rats have lesions and inflammation in the upper respiratory tract. However, lesions in the lung are very mild. Infection of suckling rats by RCoV-SDAV results in more severe respiratory disease. $\mathrm{RCoV}-\mathrm{P}$ was initially isolated from lungs of asymptomatic rats. ${ }^{11}$ In contrast with RCoVSDAV, RCoV-P is strictly pneumotropic. Inoculation of adult rats with RCoV-P causes asymptomatic infection of the upper and lower respiratory tract with focal interstitial pneumonia, while infection of neonates results in lethal interstitial pneumonia. ${ }^{11,12}$ The cellular receptor(s) used by RCoV-SDAV and RCoV-P have not been identified. RCoV-P expresses an enzymatically active hemagglutinin esterase (HE) protein on the viral

\footnotetext{
* Tanya A. Miura, Kathryn V. Holmes, University of Colorado Health Sciences Center, Aurora, Colorado 80010. Jieru Wang, Robert J. Mason, National Jewish Medical and Research Center, Denver, Colorado 80206.
} 


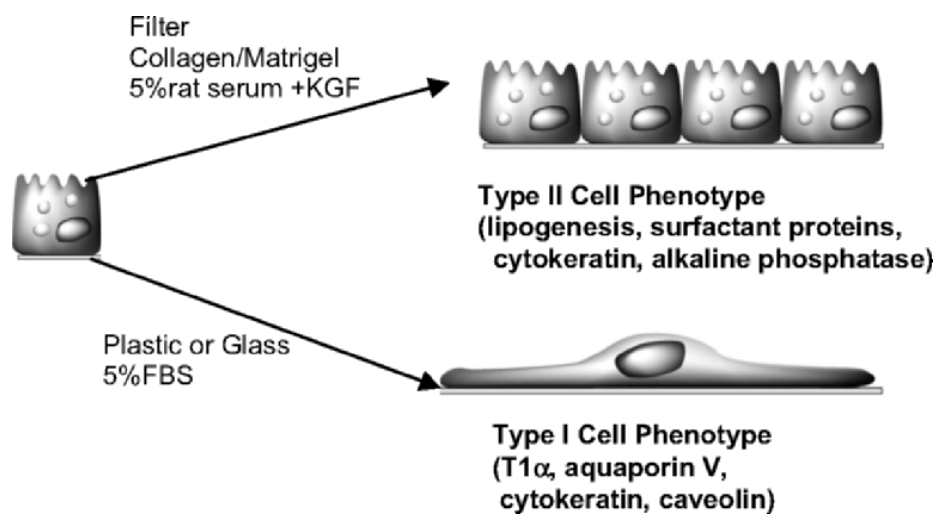

Figure 1. Primary rat alveolar epithelial cells can be cultured to maintain a type II cell phenotype or transdifferentiate into a type I cell phenotype.

envelope, whereas our laboratory isolate of RCoV-SDAV does not express HE. ${ }^{13}$ The role of the $\mathrm{HE}$ protein in $\mathrm{RCoV}$ infection and pathogenesis has not been studied.

Here we report infection of primary cultures of differentiated rat alveolar epithelial cells by RCoV-P and RCoV-SDAV. Rat type II alveolar epithelial cells can be isolated and grown under culture conditions that either maintain a type II phenotype or trans-differentiate into a type I cell phenotype (Figure 1). ${ }^{14,15}$ Type II alveolar cells are dividing, cuboidal cells that produce surfactant and regenerate the lung epithelium after injury. Type I alveolar cells are nondividing cells with a flattened morphology that mediate gas exchange and fluid homeostasis in the lung. Specific markers for differentiating type I and type II alveolar cells include surfactant proteins for type II cells and $\mathrm{T} 1 \alpha$, aquaporin $\mathrm{V}$, and caveolin for type I cells.

Respiratory coronaviruses have been studied in bronchial epithelial cells but not in alveolar epithelial cells. Cultures of differentiated rat pneumocytes can be used to evaluate the cellular tropism of viral infection, viral cytopathic effects on alveolar cells, and viral modulation of cytokines and chemokines that control the immune response and tissue damage in the host. Inoculation with RCoV-SDAV results in more rapid and extensive cell fusion of type I cells than RCoV-P. We are evaluating determinants of differential cell fusion by RCoV strains. In conclusion, the ability of coronavirus to infect both alveolar type I and type II cells has implications in the pathogenesis of severe lung disease, such as that caused by SARS-CoV.

\section{METHODS AND RESULTS}

\subsection{RCoV Infection of Primary Rat Alveolar Type II and Type I Cells}

We used freshly isolated type II cells to evaluate infection of highly differentiated pneumocytes by RCoV-SDAV and RCoV-P. Rat alveolar type II cells were isolated and inoculated in suspension with RCoV-SDAV or RCoV-P. Cells were fixed at $72 \mathrm{hpi}$ and 

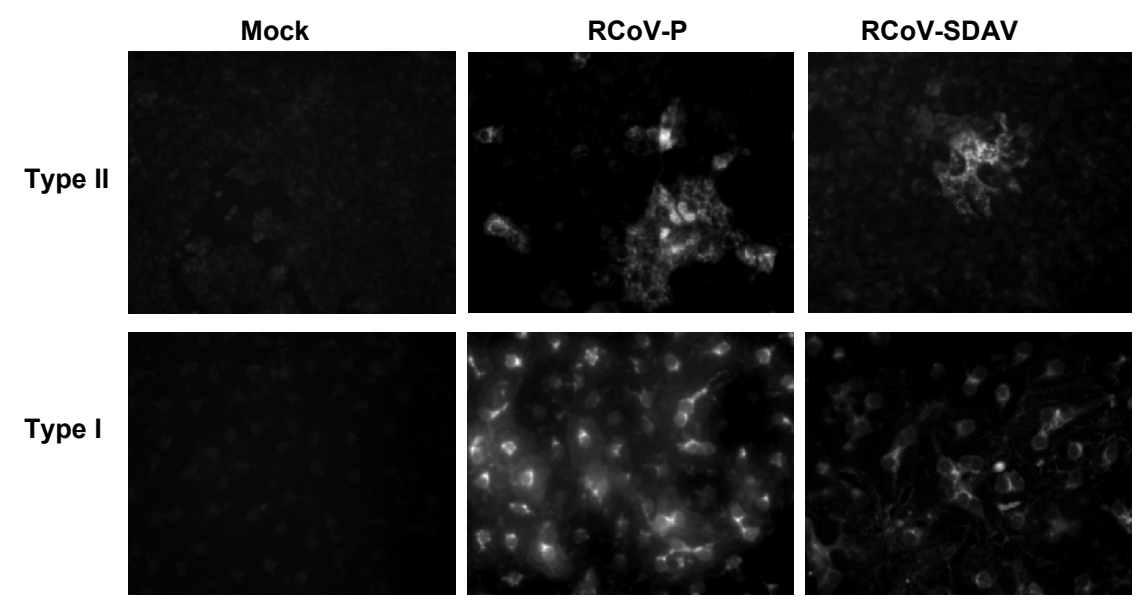

Figure 2. Primary rat alveolar epithelial cells are susceptible to infection by RCoV-P and RCoV-SDAV.

viral antigen was detected by immunofluorescence. To evaluate infection of type I phenotype cells, alveolar epithelial cells were cultured for 6 days under conditions that result in trans-differentiation into a type I cell phenotype (Figure 1) prior to virus inoculation. Viral antigen was detected in type II and type I cells that had been inoculated with RCoV-SDAV or RCoV-P but not in mock-inoculated cells (Figure 2). Infectious virus was detected in media from infected cultures (data not shown). Thus both RCoVSDAV and RCoV-P can infect primary cultures of rat alveolar type II and type I cells in vitro.

We studied a time course of RCoV infection of primary cultures of rat alveolar type I cells. Cells were incubated for 6 days to fully differentiate into a type I cell phenotype, then inoculated with RCoV-SDAV or RCoV-P. Cells and medium were collected at various times postinoculation. The titer of infectious virus in culture supernatant was determined by plaque assay on L2P41.a cells. Viral antigen was present in RCoV-SDAV and RCoV-P infected cells by 10 hours postinoculation (hpi). Infection by RCoV-SDAV resulted in the formation of syncytia by $12 \mathrm{hpi}$, which were very large by $27 \mathrm{hpi}$ (Figure 3) and were peeling off the coverslip by $51 \mathrm{hpi}$. In contrast, the RCoV-P infected cells did not form syncytia until $27 \mathrm{hpi}$, and syncytia were much smaller than those in the RCoV-SDAVinfected cells. Both RCoV-SDAV and RCoV-P grew to similar titers $\left(1.5 \times 10^{4}-3 \times 10^{4}\right.$ $\mathrm{pfu} / \mathrm{mL}$ ) in primary type I cell cultures.

\subsection{Sequence of the RCoV Spike Glycoprotein}

The spike (S) glycoprotein of coronaviruses mediates cell to cell fusion. We therefore sequenced the spike glycoprotein of RCoV-P. We found 70 nucleotide differences in the sequence of the $\mathrm{S}$ gene of RCoV-P as compared with the published sequence of the RCoVSDAV S (NCBI \#AF207551). These mutations resulted in 22 amino acid changes in the S1 

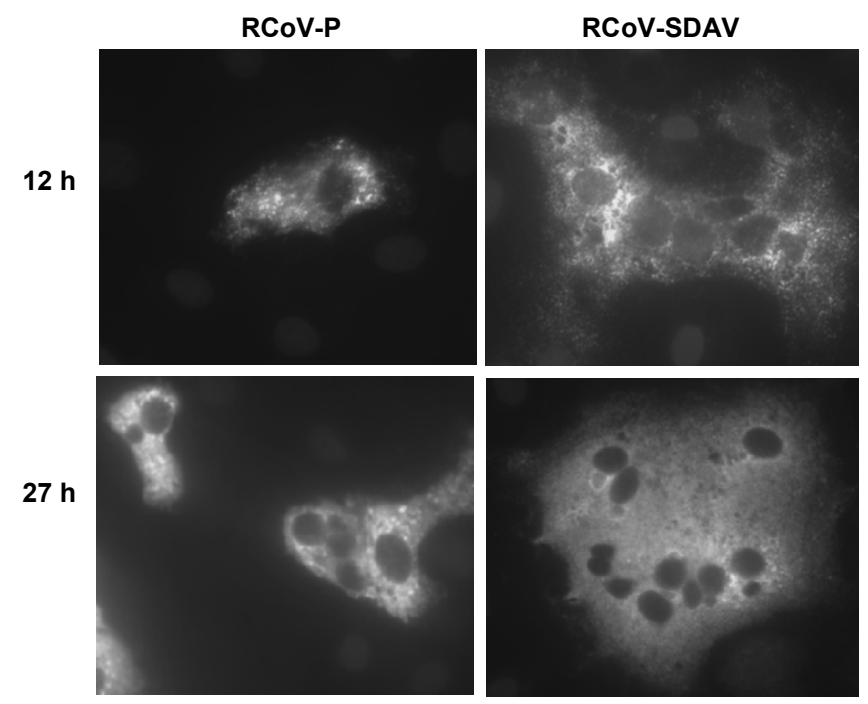

Figure 3. Infection of primary alveolar type I cells by RCoV-SDAV results in larger syncytia than infection by $\mathrm{RCoV}-\mathrm{P}$ at $12 \mathrm{~h}$ and $27 \mathrm{~h}$ post-inoculation.

region that might affect receptor binding and 9 amino acid changes in the S2 region that might affect cell fusion.

The functions of the S glycoprotein of murine coronavirus MHV have been studied extensively. ${ }^{16}$ The S proteins of MHV strains are $79-90 \%$ identical in amino acid sequence with RCoV-P and RCoV-SDAV. Four of the amino acids that were changed in RCoV-P as compared with RCoV-SDAV are shared with the non-fusogenic MHV-2 (NCBI \#AF201929). These 4 amino acids may be important for the non-fusogenic phenotype of MHV-2 and the delayed fusogenic phenotype of RCoV-P. In particular, amino acid 750 , which is located near the $\mathrm{S} 1 / \mathrm{S} 2$ cleavage signal sequence, may be important in S1/S2 cleavage and the subsequent ability of spike to mediate cell-cell fusion. Hingley et al. previously showed that substitution of the MHV-A59 cleavage signal with the corresponding amino acids of MHV-2 resulted in less efficient cleavage of S1/S2 and a delayed fusion phenotype. ${ }^{17}$ The spike glycoprotein of RCoV-SDAV grown in L2P41.a cells is completely cleaved into $90-\mathrm{kDa} \mathrm{S} 1$ and S2 proteins, while RCoV-P spike is only partially cleaved. ${ }^{13}$ Like MHV-2, RCoV-P has a threonine at amino acid 750, while RCoV-SDAV has an isoleucine. We hypothesize that changing the isoleucine 750 to threonine in the RCoV-SDAV spike would result in decreased efficiency of spike cleavage and cell fusion. Alternatively, other amino acid changes in the spike of RCoV-P may contribute to the delayed fusion phenotype seen in RCoV-Pinfected cells. The specific amino acids in spike that are important in the delayed cell to cell fusion phenotype of RCoV-P will be studied further. 


\section{DISCUSSION}

The discovery of 3 human respiratory coronaviruses since 2003 increases the need to study the pathogenesis of coronaviruses in the lung. We are studying rat coronavirus infection of primary rat alveolar epithelial cells as a model for coronavirus pathogenesis in the lung of a natural host.

We have found that rat coronaviruses infect both type I and type II alveolar epithelial cell phenotypes. ACE-2, the principal receptor for SARS-CoV, is expressed in both type I and type II pneumocytes. ${ }^{18} \mathrm{CD} 209 \mathrm{~L}$, which has been identified as an alternative receptor for SARS-CoV ${ }^{19}$ is also expressed in type I and type II pneumocytes. SARS-CoV RNA and antigen have been detected in alveolar epithelial cells of fatal SARS cases ${ }^{20,21}$ and in type I pneumocytes in infected macaques. ${ }^{22}$ Type I pneumocytes make up the majority of the epithelial surface area of the lung. Damage to type I cells interferes with gas exchange and fluid homeostasis. Injury to type I cells causes type II cells to dedifferentiate, proliferate, migrate, and trans-differentiate into type I cells to repair the damaged lung. A virus that can infect both type I and type II cells, like RCoV, could cause severe lung disease by preventing repair of the damaged epithelium. Type II cells are essential for the secretion of surfactant, which stabilizes the alveoli and prevents acute respiratory distress syndrome, and surfactant proteins that are important mediators of innate immunity. Alveolar epithelial cells elicit innate and acquired immune responses in the lung by secretion of specific cytokines and chemokines. The effects of virus infection on the immune response will be addressed in future studies.

\section{ACKNOWLEDGMENTS}

This work was supported by NIH P01-AI59576 and R01-AI25231. The authors thank Christian Pontillo and Karen Edeen for excellent technical assistance.

\section{REFERENCES}

1. L. van der Hoek, K. Pyrc, M. F. Jebbink, W. Vermeulen-Oost, R. J. Berkhout, K. C. Wolthers, P. M. Wertheim-van Dillen, J. Kaandorp, J. Spaargaren, and B. Berkhout, Identification of a new human coronavirus, Nat. Med. 10, 368-373 (2004).

2. R. A. Fouchier, N. G. Hartwig, T. M. Bestebroer, B. Niemeyer, J. C. de Jong, J. H. Simon, and A. D. Osterhaus, A previously undescribed coronavirus associated with respiratory disease in humans, Proc. Natl. Acad. Sci. USA 101, 6212-6216 (2004)

3. P. C. Woo, S. K. Lau, C. M. Chu, K. H. Chan, H. W. Tsoi, Y. Huang, B. H. Wong, R. W. Poon, J. J. Cai, W. K. Luk, et al., Characterization and complete genome sequence of a novel coronavirus, coronavirus HKU1, from patients with pneumonia, J. Virol. 79, 884-895 (2005).

4. D. O’Toole, I. Brown, A. Bridges, and S. F. Cartwright, Pathogenicity of experimental infection with 'pneumotropic' porcine coronavirus, Res. Vet. Sci. 47, 23-29 (1989).

5. J. Storz, X. Lin, C. W. Purdy, V. N. Chouljenko, K. G. Kousoulas, F. M. Enright, W. C. Gilmore, R. E. Briggs, and R. W. Loan, Coronavirus and Pasteurella infections in bovine shipping fever pneumonia and Evans' criteria for causation, J. Clin. Microbiol. 38, 3291-3298 (2000).

6. K. Erles, C. Toomey, H. W. Brooks, and J. Brownlie, Detection of a group 2 coronavirus in dogs with canine infectious respiratory disease, Virology 310, 216-223 (2003).

7. P. N. Bhatt, D. H. Percy, and A. M. Jonas, Characterization of the virus of sialodacryoadenitis of rats: a member of the coronavirus group, J. Infect. Dis. 126, 123-130 (1972).

8. Y. L. Lai, R. O. Jacoby, P. N. Bhatt, and A. M. Jonas, Keratoconjunctivitis associated with sialodacryoadenitis in rats, Invest. Ophthalmol. 15, 538-541 (1976). 
9. K. Utsumi, Y. Yokota, T. Ishikawa, K. Ohnishi, and K. Fujiwara, in: Coronaviruses and Their Diseases, edited by D. Cavanagh and T. D. K. Brown, (Plenum Press, New York, 1990), pp. 525-532.

10. Z. W. Wojcinski and D. H. Percy, Sialodacryoadenitis virus-associated lesions in the lower respiratory tract of rats, Vet. Pathol. 23, 278-286 (1986).

11. J. C. Parker, S. S. Cross, and W. P. Rowe, Rat coronavirus (RCV): a prevalent, naturally occurring pneumotropic virus of rats, Arch. Gesamte. Virusforsch. 31, 293-302 (1970).

12. P. N. Bhatt and R. O. Jacoby, Experimental infection of adult axenic rats with Parker's rat coronavirus, Arch. Virol. 54, 345-352 (1977)

13. S. Gagneten, C. A. Scanga, G. S. Dveksler, N. Beauchemin, D. Percy, and K. V. Holmes, Attachment glycoproteins and receptor specificity of rat coronaviruses, Lab. Anim. Sci. 46, 159-166 (1996).

14. L. G. Dobbs and R. J. Mason, Pulmonary alveolar type II cells isolated from rats. Release of phosphatidylcholine in response to beta-adrenergic stimulation, J. Clin. Invest. 63, 378-387 (1979).

15. R. J. Mason, M. C. Lewis, K. E. Edeen, K. McCormick-Shannon, L. D. Nielsen, and J. M. Shannon, Maintenance of surfactant protein A and D secretion by rat alveolar type II cells in vitro, Am. J. Physiol. Lung Cell. Mol. Physiol. 282, L249-258 (2002).

16. T. M. Gallagher and M. J. Buchmeier, Coronavirus spike proteins in viral entry and pathogenesis, Virology 279, 371-374 (2001)

17. S. T. Hingley, I. Leparc-Goffart, S. H. Seo, J. C. Tsai, and S. R. Weiss, The virulence of mouse hepatitis virus strain A59 is not dependent on efficient spike protein cleavage and cell-to-cell fusion, J. Neurovirol. 8, 400-410 (2002).

18. I. Hamming, W. Timens, M. L. Bulthuis, A. T. Lely, G. J. Navis, and H. van Goor, Tissue distribution of ACE2 protein, the functional receptor for SARS coronavirus. A first step in understanding SARS pathogenesis, J. Pathol. 203, 631-637 (2004).

19. S. A. Jeffers, S. M. Tusell, L. Gillim-Ross, E. M. Hemmila, J. E. Achenbach, G. J. Babcock, W. D. Thomas, Jr., L. B. Thackray, M. D. Young, R. J. Mason, et al., CD209L (L-SIGN) is a receptor for severe acute respiratory syndrome coronavirus, Proc. Natl. Acad. Sci. USA 101, 15748-15753 (2004).

20. K. F. To, J. H. Tong, P. K. Chan, F. W. Au, S. S. Chim, K. C. Chan, J. L. Cheung, E. Y. Liu, G. M. Tse, A. W. Lo, et al., Tissue and cellular tropism of the coronavirus associated with severe acute respiratory syndrome: an in-situ hybridization study of fatal cases, J. Pathol. 202, 157-163 (2004).

21. K. F. To and A. W. Lo, Exploring the pathogenesis of severe acute respiratory syndrome (SARS): the tissue distribution of the coronavirus (SARS-CoV) and its putative receptor, angiotensin-converting enzyme 2 (ACE2), J. Pathol. 203, 740-743 (2004).

22. B. L. Haagmans, T. Kuiken, B. E. Martina, R. A. Fouchier, G. F. Rimmelzwaan, G. van Amerongen, D. van Riel, T. de Jong, S. Itamura, K. H. Chan, et al., Pegylated interferon-alpha protects type 1 pneumocytes against SARS coronavirus infection in macaques, Nat. Med. 10, 290-293 (2004). 